\title{
Seasonality and time scale dependence of the relationship between turbulent surface heat flux and SST
}

\author{
Xiaoshan Sun ${ }^{1,3} \cdot$ Renguang $\mathrm{Wu}^{2,1,4,5}$ (D)
}

Received: 30 July 2020 / Accepted: 4 January 2021 / Published online: 21 January 2021

(c) The Author(s) 2021

\begin{abstract}
The present study examined the relationship between turbulent surface heat flux (SHF) and sea surface temperature (SST) variations using daily observational data. The SHF and SST relationship displays notable differences between winter and summer and prominent time-scale dependence in both seasons. In the mid-latitude SST frontal regions, SST has a larger role in driving SHF in winter than in summer. In the subtropical gyre regions, SHF plays a larger role in the SST change in summer than in winter. In winter, SHF has a larger effect on the SST change in the South China Sea than in the Arabian Sea and Bay of Bengal. In summer, the SST effect on SHF is dominant in the Arabian Sea, whereas the SHF impact on SST is dominant in the Philippine Sea. In the Gulf Stream, Kuroshio Extension and Agulhas Return Current, the SST effect extends up to 90-day time scales in winter, the SHF impact is limited to time scales below 20 days and the SST effect is dominant on time scales above 20 days in summer. In winter, the SHF effect extends up to 90-day time scales in the Bay of Bengal, South China Sea, and Philippine Sea, but is limited to time scales below 40 days in the Arabian Sea. In summer, the SST effect extends up to 90-day time scales in the Arabian Sea, whereas the SHF and SST effect is large on time scales shorter and longer than 40 days, respectively, in the Philippine Sea.
\end{abstract}

Keywords Surface heat flux-SST relationship $\cdot$ Seasonal difference $\cdot$ Time-scale dependence $\cdot$ The mid-latitude frontal zone $\cdot$ The subtropical gyre region · Tropical Indo-Western Pacific

\section{Introduction}

Ocean and atmosphere interact in various manners. One of the ocean-atmosphere interaction processes is the exchange of turbulent heat fluxes. On one hand, the upper ocean may

Renguang Wu

renguang@zju.edu.cn

1 Center for Monsoon System Research, Institute of Atmospheric Physics, Chinese Academy of Sciences, Beijing, China

2 School of Earth Sciences, Zhejiang University, Hangzhou 310027, China

3 College of Earth and Planetary Sciences, University of Chinese Academy of Sciences, Beijing, China

4 State Key Laboratory of Numerical Modeling for Atmospheric Sciences and Geophysical Fluid Dynamics, Institute of Atmospheric Physics, Chinese Academy of Sciences, Beijing, China

5 Southern Marine Science and Engineering Guangdong Laboratory (Zhuhai), Zhuhai, China supply heat to the atmosphere by modulating the sea-air humidity and temperature differences. On the other hand, the atmosphere can change the thermal condition of the upper ocean through wind-induced turbulent heat fluxes.

The importance of ocean-atmosphere interactions has been demonstrated by many studies, which have reported discrepancies in the precipitation variability and precipitation-sea surface temperature (SST) relationship between stand-alone atmospheric model simulations and the observations (Sperber and Palmer 1996; Kumar and Hoerling 1998; Wang et al. 2005; Wu et al. 2006; Wu and Kirtman 2007; Wu and You 2018) and between forced and coupled model simulations (Barsugli and Battisti 1998; Kitoh and Arakawa 1999; Lau and Nath 2000, 2003; Wu and Kirtman 2004, 2005, 2007; Wu et al. 2006). These discrepancies are attributed to the lack of air-sea interactions in the stand-alone atmospheric model simulations and to the misrepresentation of the air-sea relationship in the coupled model simulations. Therefore, revealing the seasonal and spatial changes as well as the time scale dependence of the ocean-atmosphere relationship is essential for 
understanding the climate variability and the performance of climate model simulations.

The local lead-lag correlation between rain rate or surface turbulent heat flux (SHF) and SST or local simultaneous correlation or covariance between rain rate or SHF and SST and SST tendency, which is the temporal derivative of SST, have been diagnosed to help the understanding of the air-sea relationship in previous studies (Frankignoul and Hasselmann 1977; Frankignoul 1985; Wallace et al. 1990; Cayan 1992; Barsugli and Battisti 1998; Frankignoul et al. 1998; von Storch 2000; Wu and Kirtman 2005, 2007; Wu et al. 2006, 2007, 2015; Ye and Wu 2015; Bishop et al. 2017; Wu and You 2018; Wu 2019; Small et al. 2019). The representation of air-sea relationship using local correlation of SHF with SST and SST tendency has been illustrated using a simple stochastic model (Barsugli and Battisti 1998; Wu et al. 2006; Bishop et al. 2017). There is a marked difference in the SHF-SST and SHF-SST tendency correlation between the atmospheric and oceanic forcing cases. In the case of oceanic forcing, a positive correlation exists between SHF (positive denoting upward) and SST, indicating warmer water heating the overlying atmosphere by upward SHF. In the case of atmospheric forcing, a negative correlation exists between the SHF and SST tendency, indicating more upward SHF lowering SST.

Previous studies revealed the spatial change in the SHF and SST relationship. Bishop et al. (2017) showed that the SHF-SST and SHF-SST tendency relationship displays a pronounced difference between the western boundary currents in the mid-latitude oceans and the subtropical mid-ocean gyres. Along the western boundary current and the Antarctic Circumpolar Current regions, large positive SHF-SST correlation is observed, indicating that SST drives the SHF change in those regions. In the mid-ocean gyre regions, prominent negative SHF-SST tendency is observed, indicating that SHF drives the SST change. Similar results were obtained by Small et al. (2019) with multiple turbulent heat flux data. Wu and Kinter (2010) identified a difference in the surface latent heat flux (LHF, a dominant part of SHF over the ocean) and SST relationship between the western and central part of the midlatitude North Pacific. In the central part, LHF is a driving factor of SST anomalies in both winter and summer. In the western part, SST induces LHF anomalies that in turn feedback on the SST change in boreal winter. The spatial change in the LHF and SST relationship has been also detected in the tropical Indo-western Pacific region (Wu et al. 2006; Duvel and Viallard 2007; Ye and Wu 2015; Wu et al. 2015). For example, Duvel and Viallard (2007) showed that the LHF drives the intraseasonal SST variation in the Indian Ocean and north of Australia in boreal winter and the effect of LHF is small in the western Pacific.
Previous studies identified the seasonal variation in the SHF and SST relationship. Bishop et al. (2017) found that the SHF-SST covariance along the Gulf Stream and Kuroshio Extension is largest in boreal winter. Wu and Kinter (2010) showed that the impact of LHF on the interannual SST anomalies in the western part of the mid-latitude North Pacific is prominent in boreal winter but weak in boreal summer. Jin et al. (2020) found that the coherence between the intraseasonal variations of SHF and vertical heat transport at $50 \mathrm{~m}$ along the Kuroshio Extension is larger in boreal winter than in boreal summer. Seasonal variations of the LHF and SST relationship have also been observed in the tropical Indo-western Pacific region (Duvel and Viallard 2007; Wu et al. 2015). Duvel and Viallard (2007) found that the LHF impact on intraseasonal SST variations in the Arabian Sea, north of the Bay of Bengal, and China Sea is larger in boreal summer. Wu et al. (2015) obtained a larger coherence between intraseasonal LHF and SST variations in the western North Pacific in boreal summer than in boreal winter.

The time scale dependence of the SHF and SST relationship has been detected in a few studies. Bishop et al. (2017) showed that the SHF-SST correlation along the Gulf Stream, Kuroshio Extension, and Agulhas Return Current becomes larger when the time scale changes from a few months to 1-2 years, indicative of an increase of the oceanic influence with the time scale in the mid-latitude SST frontal zones. Small et al. (2019) found that the magnitude of simultaneous SHF-SST correlation changes largely with the time window of smoothing used before calculating the correlation in the northwest Pacific and Atlantic regions. Jing et al. (2020) obtained a large coherence between SHF and vertical heat transport at $50 \mathrm{~m}$ in the Kuroshio Extension on intraseasonal time scales. Ye and $\mathrm{Wu}(2015)$ and $\mathrm{Wu}$ et al. (2015) found a larger contribution of LHF to intraseasonal SST variations in the tropical western North Pacific on 30-60-day than 10-20-day time scales.

The SST tendency can be approximately explained by total SHF and ocean heat flux convergence driven by ocean advection. The relative contribution of total SHF and ocean advection to the SST change determines to a large extent the SHF and SST relationship. The contribution of SHF to the SST change depends upon the ocean mixed-layer depth and the amplitude of SHF perturbations. In small ocean mixedlayer depth regions, the contribution of SHF to the SST change tends to be large. In such regions, the SHF and SST relationship likely belongs to the atmosphere-driven case, such as the central part of the mid-latitude North Pacific (Wu and Kinter 2010) and the tropical North Indian Ocean and western North Pacific in boreal summer (Duvel and Viallard 2007; Ye and Wu 2015; Wu et al. 2015). In regions with large atmospheric perturbations, such as the tropical Indian Ocean in boreal winter where intraseasonal oscillations are strong, the amplitude of SHF anomalies may be 
large and the SST response to SHF is prominent (Duvel and Viallard 2007). The contribution of ocean advection to the SST change depends upon the mean SST gradient and the magnitude of ocean current anomalies. In weak SST gradient regions, such as the subtropical gyre regions, the contribution of ocean advection is expected to be small and thus SST is likely driven by SHF (Bishop et al. 2017; Small et al. 2019). In strong SST gradient regions, the ocean advection may contribute largely to the SST change. The impact of the SST gradient is prominent in the mid-latitude SST frontal zones, such as the Gulf Stream, Kuroshio Extension and Agulhas Return Current (Bishop et al. 2017; Small et al. 2019).

The SHF and SST relationship has been analyzed using monthly data (Wu et al. 2006; Wu and Kinter 2010; Bishop et al. 2017; Small et al. 2019). The atmosphere has high frequency variations that may contribute to the upper ocean variation (Hassleman 1976; Wallace et al. 1990). Deser and Timlin (1997) indicated that the coupling between SST and 500-hPa geopotential height variations in the mid-latitude North Pacific and North Atlantic reaches the strongest when the atmospheric variability leads SST by $2-3$ weeks, which cannot be resolved using monthly data. In addition, simultaneous correlation derived based on monthly mean data may include the effect of atmospheric persistence as daily anomalies may be maintained for weeks and contribute to monthly mean anomalies (Frankignoul and Hasselmann 1976; Frankignoul et al. 1998). Further, the correlation calculated based on monthly mean may be reduced compared to that calculated based on daily mean (Wu et al. 2006). Small et al. 2019 showed that the 30-day mean leads to a much higher simultaneous SHF-SST correlation than the 1-day mean in the northwest Pacific and Atlantic regions. Some previous studies analyzed the air-sea relationship based on daily data (Duvel and Viallard 2007; Ye and Wu 2015; Wu et al. 2015; Jin et al. 2020). For example, Ye and Wu (2015) and $\mathrm{Wu}$ et al. (2015) found that the 10-20-day and 30-60day intraseaseasonal SHF and SST variations have different spatial structure and strength of coherence in the tropical western North Pacific. However, it is unknown whether and at which time scale there is a transition between the atmosphere-driven and ocean-driven regimes. Thus, it is worthy of further investigation regarding the regional feature, seasonal variation, and time scale dependence in the SHF and SST relationship using the daily data.

The present study compares the SHF and SST relationship in winter and summer and the change of the SHF and SST relationship with the time scale in winter and summer in the mid-latitude SST frontal regions, the subtropical gyre regions, and the tropical Indo-western Pacific regions. The rest of the paper is organized as follows. Section 2 introduces the observation datasets and methods. In Sect. 3, we present the results of a stochastic model simulations serving as a physical rationale of understanding the local SHF and SST relationship. In Sect. 4, we present the regional feature of the SHF-SST and SHF-SST tendency covariance. In Sect. 5, we contrast the lead-lag correlation of SHF and SST variations between winter and summer at selected locations to illustrate the seasonal variation of the relationship. In Sect. 6, we document the time scale dependence of lead-lag correlation of SHF and SST variations at a few locations. Section 7 provides the summary of results and discussions.

\section{Datasets and methods}

This study uses daily SST of the National Oceanic and Atmospheric Administration (NOAA) Optimum Interpolation Sea Surface Temperature (OISST) v2.0 (Reynolds et al. 2007). The OISST data are available from 1981 to 2020 with a spatial resolution of $0.25^{\circ}$ grid. The OISST data were obtained from ftp://ftp.cdc.noaa.gov/Datasets/noaa.oisst.v2. highres/.

The daily SHF data are from the objectively analyzed air-sea sensible heat and latent heat fluxes (OAFlux) product of the Woods Hole Oceanographic Institution (Yu and Weller 2007). The OAFlux flux data have a $1^{\circ}$ spatial resolution and cover the time period from 1985 to 2018. We obtained the OAFlux turbulent SHF via ftp://ftp.whoi.edu/ pub/science/oaflux/data_v3/daily/turbulence/.

We interpolate the OAFlux SHF to $0.25^{\circ}$ spatial grids to match the NOAA OISST SST data in the analysis of local SHF and SST relationship. We note that SHF tends to display smoother spatial features than SST along the mid-latitude SST frontal zones. As such, interpolating SHF to higher resolution does not alter the spatial distribution of SHF so that the analysis can retain the spatial structure of the SHF and SST relationship. The time period of analysis extends from January 1, 1985 to December 31, 2018.

Local simultaneous grid-point covariance between SHF and SST and between SHF and SST tendency are analyzed for all the months as well as for the winter months (November-March/May-September, NDJFM/MJJAS in brief) and summer months (MJJAS/NDJFM) of the Northern/Southern Hemisphere, respectively, to examine the seasonal change of the relationship. The lead-lag correlation between SHF and SST or SST tendency is calculated for the winter and summer months, respectively, at selected locations. The SST tendency at a specific day is obtained by the difference of the succeeding day SST minus the preceding day SST divided by 2 . The SHF is the sum of sensible heat flux and latent heat flux. The convention of SHF is that positive value represents upward flux. We note that sensible heat flux is usually much smaller than latent heat flux over the ocean.

The statistical significance of the SHF-SST and SHF-SST tendency covariances is estimated based on the 
effective sample size ( $\left.\mathrm{n}_{\text {effective }}\right)$ calculated using the method of Preisendorfer (1988):

$\mathrm{n}_{\text {effective }}=n \times\left(\frac{1-r^{2}}{1+r^{2}}\right)$,

where $\mathrm{r}$ is the correlation coefficient and $\mathrm{n}$ is the total sample size, i.e., the number of all the days in the calculation of SHF-SST covariance. For the SHF-SST tendency covariance, $\mathrm{n}$ is set to the number of all the days divided by 2 because each daily value is used twice in the calculation of SST tendency except for the first and the last day. After $\mathrm{n}_{\text {effective }}$ is calculated for all the grid points, the smallest one $\left(\mathrm{n}_{\text {effective }}\right)_{\min }$ is used to obtain the critical correlation coefficient $\left(r_{c}\right)$ at the $95 \%$ confidence level based on the Student's $t$ test. The critical value $r_{c}$ of the SHF-SST correlation for the North Atlantic, the North Pacific, the Southern Ocean and the tropical North Indian Ocean-western North Pacific is $0.025,0.019,0.021$ and 0.024 , respectively. For the SHF-SST tendency correlation, the critical value $r_{c}$ in the above regions is $0.033,0.027,0.030$ and 0.028 , respectively.

A 2-90-day running mean of the daily data is used in the calculation of the lead-lag correlation between SHF and SST/SST tendency to diagnose the time-scale dependence of the relationship. The winter spans from December 15 to February 14 and the summer covers from June 15 to August 15 in the calculation of the above lead-lag correlation. This avoids the inclusion of signal in other seasons in the calculation of correlation for summer and winter using the running mean.

To estimate the error margins of the SHF-SST and SHF-SST tendency correlation coefficients, we calculate the SHF-SST and SHF-SST tendency correlations by adding/subtracting the SHF and SST errors, which are included in the heat flux and SST datasets, to/from the daily mean SHF and SST values. As such, we obtain four additional correlation coefficients at each grid point. Then, we obtain the maximum and minimum values of those four correlation coefficients. The differences of those maximum and minimum correlation coefficients from the correlation coefficients based on original SHF and SST is used as an indication of the error margins of the SHF-SST and SHF-SST tendency correlations.

We performed a parallel analysis using SST and turbulent SHF from the Japanese Ocean Flux (J-OFURO) data obtained from http://dtsv.scc.u-tokai.ac.jp/j-ofuro/. The J-OFURO flux data have a $1 \% / 4^{\circ}$ spatial resolution and cover the time period from 2002 to 2013 . We have compared the results based on the OAFlux and J-OFURO data and the results are in good agreement in general. The present analysis focuses on the results based on the OAFlux data with short descriptions of the results based on the J-OFURO data.

\section{Stochastic model simulations}

Before presenting the analysis of the SHF and SST relationship in the observations, we illustrate different cases derived from a stochastic model in this section. The SHF and SST relationship in those different cases serve as a rationale of understanding the different types of the SHF and SST relationship obtained from the observational analysis. The stochastic model used in this study was developed by Barsugli and Battisti (1998) and further extended by Bishop et al. (2017) to include the stochastic forcing for both the atmosphere and ocean:

$\frac{d T_{a}}{d t}=\alpha\left(T_{o}-T_{a}\right)-\gamma_{a} T_{a}+N_{a}$,

$\frac{d T_{o}}{d t}=\beta\left(T_{a}-T_{o}\right)-\gamma_{o} T_{o}+N_{o}$,

where $T_{a}$ and $T_{o}$ are surface air and ocean temperature, respectively, $\alpha$ and $\beta$ are the heat exchange coefficients of the atmosphere and ocean, respectively, $\gamma_{\mathrm{a}}$ and $\gamma_{\mathrm{o}}$ are the radiative damping coefficients of $T_{a}$ and $T_{o}$, respectively, and $N_{a}$ and $N_{o}$ denote the stochastic forcing in the atmosphere and ocean, respectively. Following Bishop et al. (2017), the stochastic forcing is represented as a forcing frequency $\omega$ multiplied by a random number with absolute values less than $1^{\circ} \mathrm{C}$. The atmospheric forcing frequency $\omega_{a}$ is set to $2 \times 10^{-5} \mathrm{~s}^{-1}$. We consider three oceanic forcing frequency cases: $\omega_{0}=2 \times 10^{-7} \mathrm{~s}^{-1}, \omega_{\mathrm{o}}=2 \times 10^{-6} \mathrm{~s}^{-1}$, and $\omega_{\mathrm{o}}=8 \times 10^{-6} \mathrm{~s}^{-1}$. The values of $\alpha, \beta, \gamma_{\mathrm{a}}$, and $\gamma_{\mathrm{o}}$ used in the stochastic model simulations are adopted from Bishop et al. (2017): $\alpha=23.9 \times 10^{-7} \mathrm{~s}^{-1}, \beta=1.195 \times 10^{-7} \mathrm{~s}^{-1}$, $\gamma_{\mathrm{a}}=2.8 \times 10^{-7} \mathrm{~s}^{-1}$, and $\gamma_{\mathrm{o}}=9.5 \times 10^{-9} \mathrm{~s}^{-1}$. Table 1 lists the values of the above parameters.

The lead-lag correlation between SHF and SST and between SHF and SST tendency derived based on the stochastic model simulations are displayed in Fig. 1 for the three oceanic forcing frequency cases. The SHF in the model is the difference of $T_{o}$ minus $T_{a}$, multiplied by the coefficient $\alpha$ and SST is $T_{o}$. The SST tendency is calculated using the central difference of $T_{o}$. In the case of $\omega_{0}=2 \times 10^{-7} \mathrm{~s}^{-1}$, the

Table 1 Parameters used in the stochastic model simulations

\begin{tabular}{lcc}
\hline Parameter & $\begin{array}{l}\text { Atmosphere forcing } \\
\left(\mathrm{s}^{-1}\right)\end{array}$ & Ocean forcing $\left(\mathrm{s}^{-1}\right)$ \\
\hline$\alpha$ & $23.9 \times 10^{-7}$ & $23.9 \times 10^{-7}$ \\
$\beta$ & $1.195 \times 10^{-7}$ & $1.195 \times 10^{-7}$ \\
$\gamma_{\mathrm{a}}$ & $2.8 \times 10^{-7}$ & $2.8 \times 10^{-7}$ \\
$\gamma_{\mathrm{o}}$ & $9.5 \times 10^{-9}$ & $9.5 \times 10^{-9}$ \\
$\omega_{\mathrm{a}}$ & $2.0 \times 10^{-5}$ & $2 \times 10^{-5}$ \\
\hline
\end{tabular}




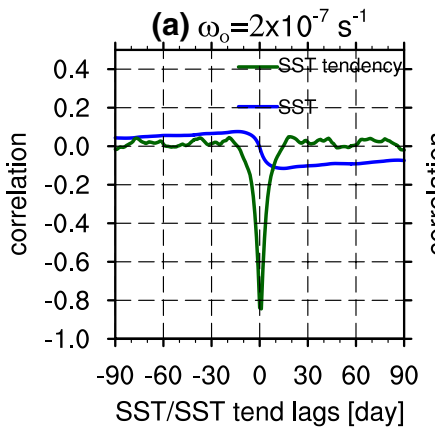

Fig. 1 Lead-lag correlation of SHF-SST (blue curves) and SHF-SST tendency (green curves) based on the stochastic model simulations with $\omega_{\mathrm{a}}=2 \times 10^{-5} \mathrm{~s}^{-1}$ and $\mathbf{a} \omega_{\mathrm{o}}=2 \times 10^{-7} \mathrm{~s}^{-1}, \mathbf{b} \omega_{\mathrm{o}}=2 \times 10^{-6} \mathrm{~s}^{-1}$, and

SHF-SST correlation is weak and the SHF-SST tendency correlation is large negative at the zero lag (Fig. 1a). This represents the atmosphere-driven case (Bishop et al. 2017). In the case of $\omega_{0}=8 \times 10^{-6} \mathrm{~s}^{-1}$, the SHF-SST correlation is large positive and symmetric about the zero lag and the SHF-SST tendency correlation is weak with a switch from positive to negative at the zero lag (Fig. 1c). This represents the ocean-driven case (Bishop et al. 2017). In the case of $\omega_{\mathrm{o}}=2 \times 10^{-6} \mathrm{~s}^{-1}$, the SHF-SST correlation is positive with an asymmetric feature and the SHF-SST tendency correlation is negative at the zero lag (Fig. 1b). The negative SHF-SST tendency correlation is smaller compared to Fig. 1a. The positive SHF-SST correlation is smaller c $\omega_{\mathrm{o}}=8 \times 10^{-6} \mathrm{~s}^{-1} . \mathrm{X}$ axis represents SST/SST tendency leading (left) and lagging (right) time in days. $\mathrm{Y}$ axis represents the correlation coefficient

compared to Fig. 1c. This case represents a situation with both oceanic forcing and atmospheric feedback. The magnitude of correlation coefficients calculated based on daily mean is smaller compared to that calculated using monthly mean (Bishop et al. 2017). This indicates an effect of time smoothing on the correlation (Small et al. 2019).

The change of the lead-lag correlation with the time scale derived from the stochastic model simulations are displayed in Fig. 2 for the three oceanic forcing frequency cases. In the atmosphere-driven case, both the magnitude and lead time of peak positive SHF-SST correlation increase with the time scale (Fig. 2a). The peak negative SHF-SST tendency correlation weakens with the increase of the time scale and
Fig. 2 Time-scale dependence of lead-lag correlation of SHF-SST (a-c) and SHF-SST tendency $(\mathbf{d}-\mathbf{f})$ based on the stochastic model simulations with $\omega_{\mathrm{a}}=2 \times 10^{-5} \mathrm{~s}^{-1}$ and $\mathbf{a}, \mathbf{d} \omega_{\mathrm{o}}=2 \times 10^{-7} \mathrm{~s}^{-1}, \mathbf{b}$, $\mathbf{e} \omega_{0}=2 \times 10^{-6} \mathrm{~s}^{-1}$, and $\mathbf{c}, \mathbf{f}$ $\omega_{\mathrm{o}}=8 \times 10^{-6} \mathrm{~s}^{-1}$. X axis represents SST/SST tendency leading (left) and lagging time in days. $\mathrm{Y}$ axis represents the time scale (days)
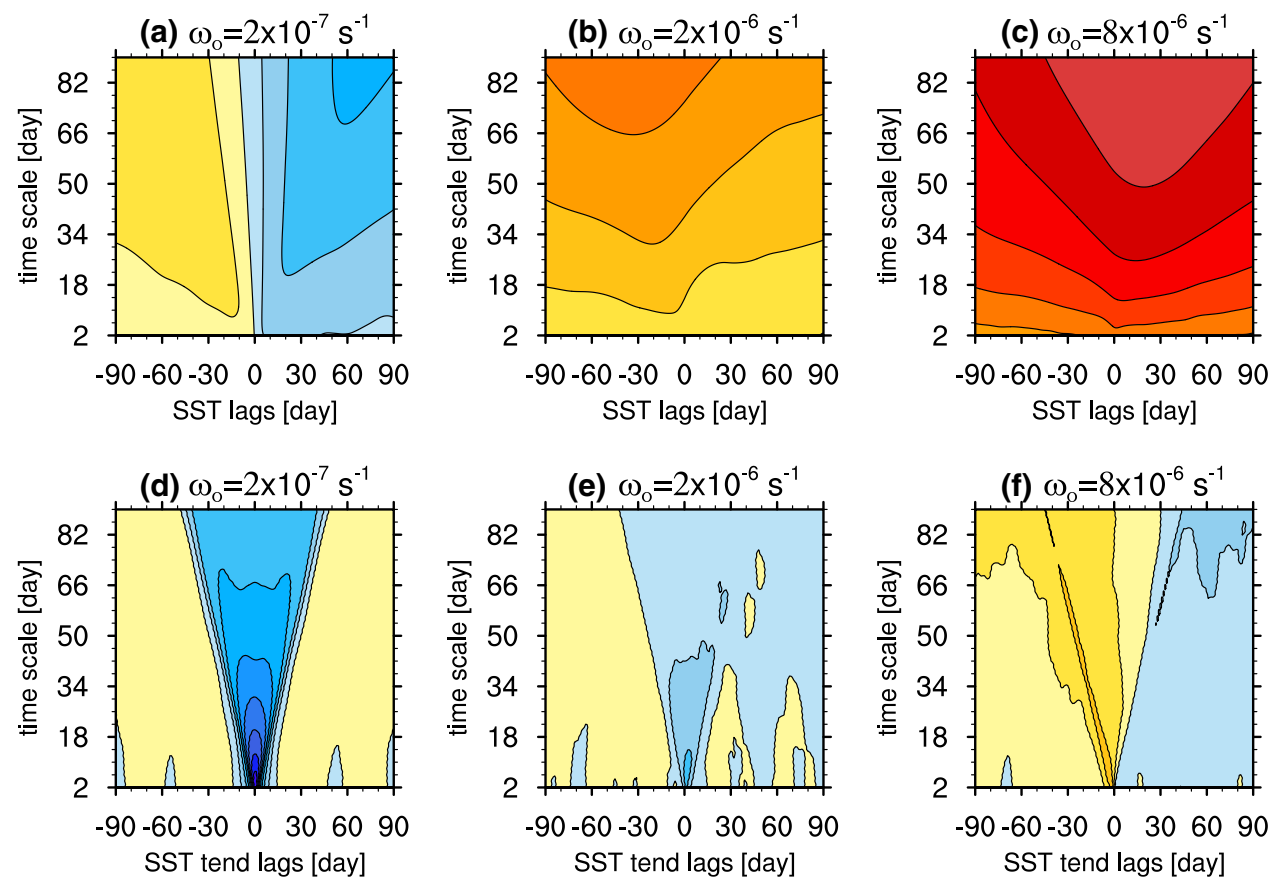

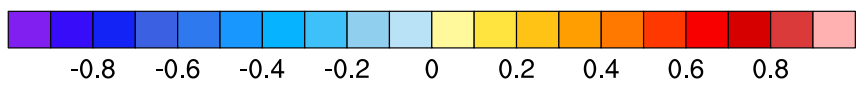


the lead and lag time covered by the negative correlation expands with the time scale (Fig. 2d). In the ocean-driven case, the peak positive SHF-SST correlation increase with the time scale (Fig. 2c), so are the positive SHF-SST tendency correlation at lead time and the negative SHF-SST tendency correlation at lag time (Fig. 2f). In the both oceanic and atmospheric forcing case, the asymmetric feature of the SHF-SST correlation is maintained with the time scale change (Fig. 2b). The magnitude and lead time of the peak SHF-SST correlation increase with the time scale. The peak negative SHF-SST tendency correlation weakens with the time scale at the beginning and then is maintained with an increase of the lag time (Fig. 2e).

\section{Regional feature of the covariance}

In this section, we analyze the covariance of SHF with SST and SST tendency in the mid-latitude North Pacific, midlatitude North Atlantic, and mid-latitude Southern Ocean as well as in the tropical North Indian Ocean and western
North Pacific. Figure 3 show the simultaneous SHF-SST covariance and SHF-SST tendency covariance in four ocean regions. They are the North Atlantic (Fig. 3a, b), North Pacific (Fig. 3c, d), South Atlantic-Indian Ocean (Fig. 3e, f), and tropical North Indian-western North Pacific Ocean (Fig. 3g, h).

In the western boundary currents (WBCs) (the Gulf Stream and Kuroshio Extension) and the Agulhas Return Current (ARC), the SHF-SST covariance is large positive (Fig. 3a, c, e), and the SHF-SST tendency covariance is large negative (Fig. 3b, d, f). In the subtropical ocean gyre regions, the SHF-SST covariance is small, and the SHF-SST tendency covariance is negative, especially in the North Pacific and South Indian Ocean.

The spatial distribution of the SHF-SST and SHF-SST tendency covariance in the North Pacific, North Atlantic, and Southern Ocean based on the daily data is similar to that based on monthly data (Bishop et al. 2017; Small et al. 2019). This is likely due to that the effect of mean state, such as the SST gradient, does not vary with the time scale. Along the SST frontal zones, the ocean advection may play
Fig. 3 Simultaneous covariance of SHF-SST (left) and SHFSST tendency (right) $\left({ }^{\circ} \mathrm{C} \mathrm{W}\right.$ $\mathrm{m}^{-2}$ ) in $\mathbf{a}, \mathbf{b}$ the North Atlantic, $\mathbf{c}, \mathbf{d}$ the North Pacific, $\mathbf{e}, \mathbf{f}$ the Southern Ocean, and $\mathbf{g}, \mathbf{h}$ the tropical North Indian Oceanwestern North Pacific. The two black diamonds in $\mathbf{a}-\mathbf{d}$ are the locations within and outside of the western boundary current extensions. The two black diamonds in $\mathbf{e}-\mathbf{f}$ are the locations within and outside of the Agulhas Return Flow. The four black diamonds in $\mathbf{g}, \mathbf{h}$ are the locations within the Arabian Sea, the Bay of Bengal, the South China Sea, and the Philippine Sea. The white areas denote the correlation coefficient below the 95\% confidence level according to the Student's $t$ test

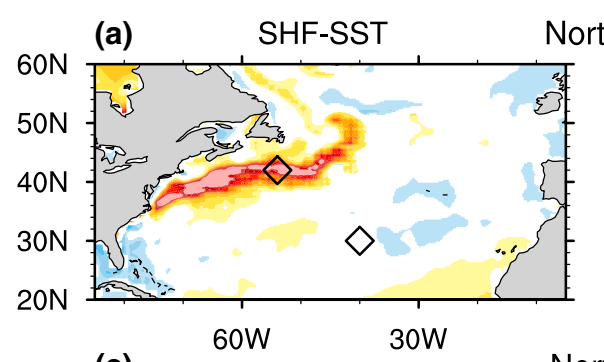

North Atlantic
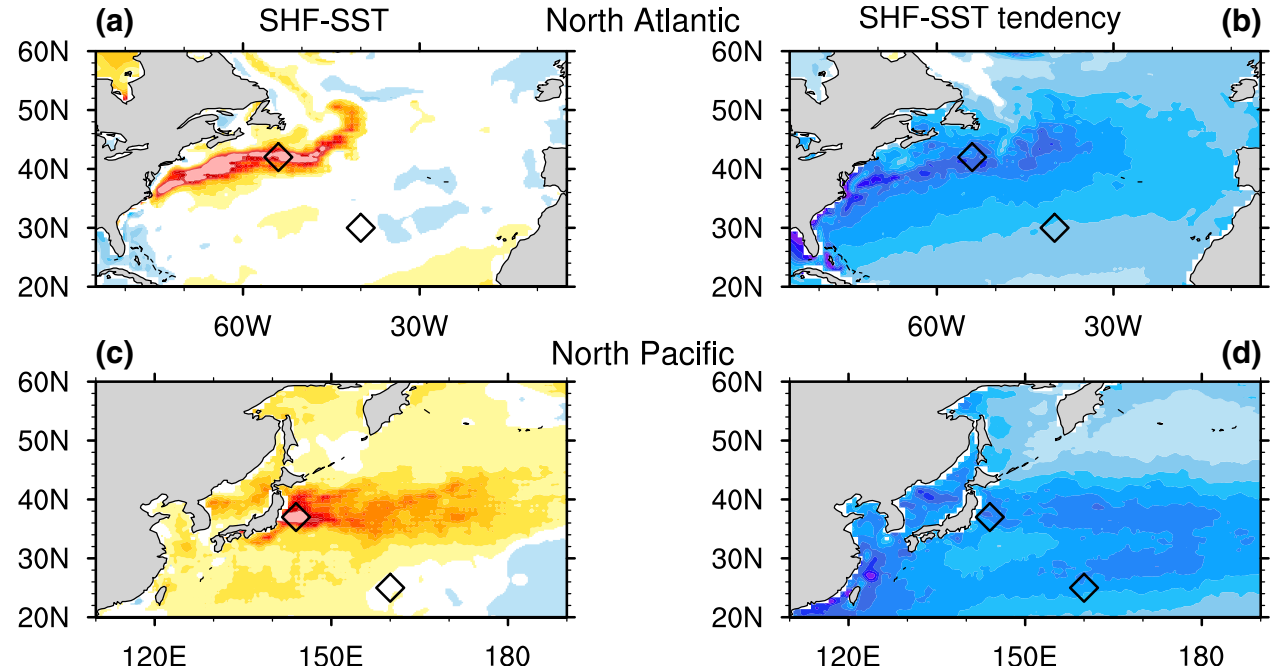
North Pacific

(d)
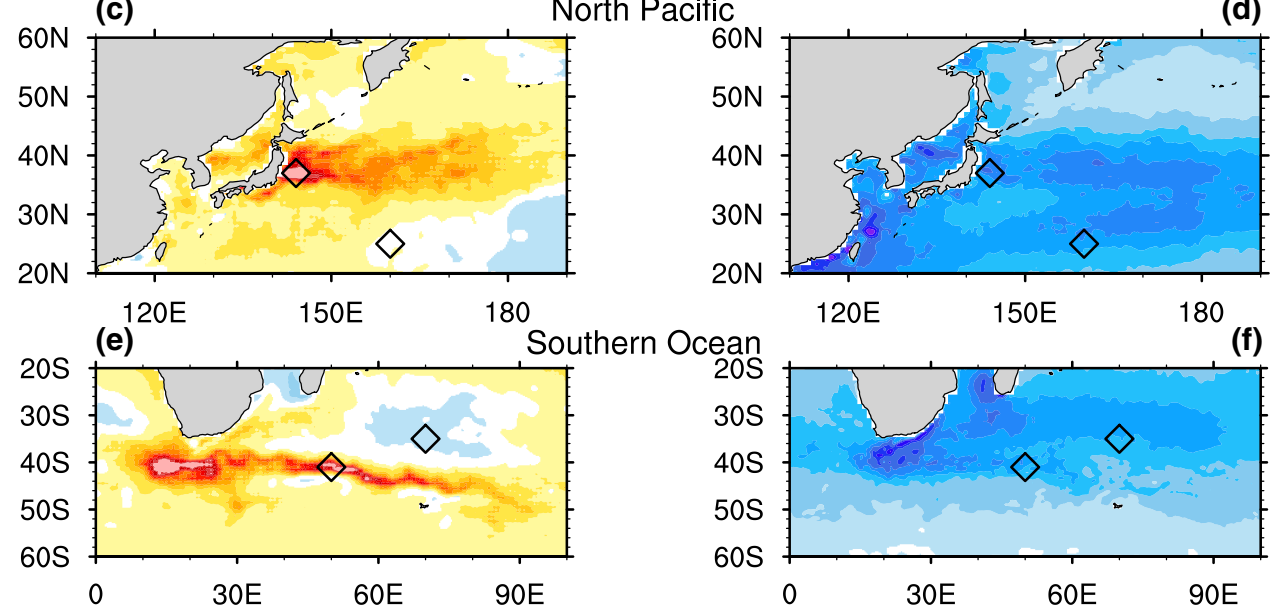

(g)

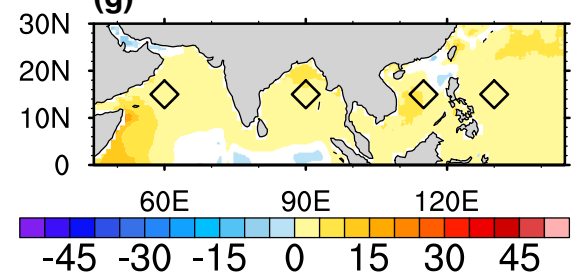

Tropical

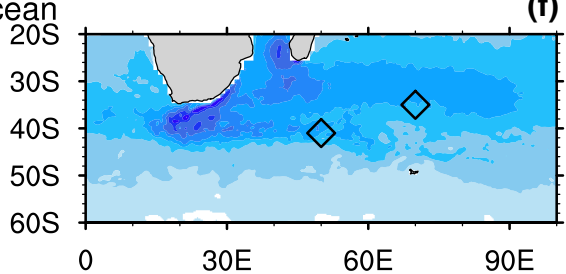

(h) 
a large role in the SST change that then induces the SHF change (Bishop et al. 2017). In the subtropical gyre regions, the contribution of oceanic processes to the SST change is small and the SHF contribution to the SST change is large. In comparison, the SHF-SST tendency covariance is larger based on the daily data than that based on the monthly data. This may be attributed to larger daily SHF variance than monthly SHF variance.

The positive SHF-SST covariance is relatively small in the tropical North Indian Ocean and western North Pacific (Fig. $3 \mathrm{~g}$ ). This is likely due to smaller SST variance in the above regions than in the WBC regions (Wu et al. 2015). Note that the positive SHF-SST covariance is relatively large off the east coast of Africa, in particular, in boreal summer (not shown). The negative SHF-SST tendency covariance is larger in the South China Sea and subtropical western North Pacific (Fig. 3h). This feature is likely related to the East Asian winter monsoon activity that induces large SHF variance over the East Asian marginal seas in boreal winter (Wu et al. 2015). The SHF perturbations in those regions then induce large intraseasonal SST changes ( $\mathrm{Wu}$ and $\mathrm{Chen}$ 2015; Wu 2016).

The analysis based on the J-OFURO data leads to quite similar features in the spatial distribution of the SHF-SST and SHF-SST tendency covariance (not shown). In comparison, the positive SHF-SST covariance is larger, whereas the negative SHF-SST tendency covariance is smaller in the WBCs, ARC, and tropical North Indian and western North Pacific likely due to the higher spatial resolution, which leads to a larger SST gradient and consequently a larger effect of ocean advection.

\section{Seasonality of lead-lag correlation at different locations}

The previous section provides evidence for the relative importance of oceanic and atmospheric forcing in different regions. In this section, we examine the lead-lag SHF-SST and SHF-SST tendency correlation in winter and summer at specific locations. We select three points in the mid-latitude SST frontal zones (one within the Gulf Stream, one within the Kuroshio Extension, and one within the Agulhas return flow), three points in the subtropical gyre regions (one within the North Atlantic, one within the North Pacific, and one within the Southern Ocean), and four points in the tropical North Indian Ocean and western North Pacific (one within the Arabian Sea, one within the Bay of Bengal, one within the South China Sea, and one within the Philippine Sea). The points are denoted by black diamonds in Fig. 3 . The six points in the mid-latitude and subtropics are selected to represent different types of air-sea relationship (Bishop et al. 2017). We present the SHF-SST and SHF-SST tendency correlation from 30-day lead to 30-day lag. The correlation at the three locations in the mid-latitude region is displayed in Fig. 4. The correlation at the three locations in the subtropical region is displayed in Fig. 5. The correlation at the four locations in the tropics is displayed in Fig. 6.

In winter, the SHF-SST correlation is large positive and the SHF-SST tendency correlation is small in the Gulf Stream (Fig. 4a), Kuroshio Extension (Fig. 4c), and ARC (Fig. 4e). The peak SHF-SST correlation occurs when SST leads SHF by about 2 days. The SHF-SST correlation falls slowly when SST leads or lags SHF. The above correlation tells that higher SST is followed by larger SHF and larger SHF is accompanied by small negative SST tendency. This is
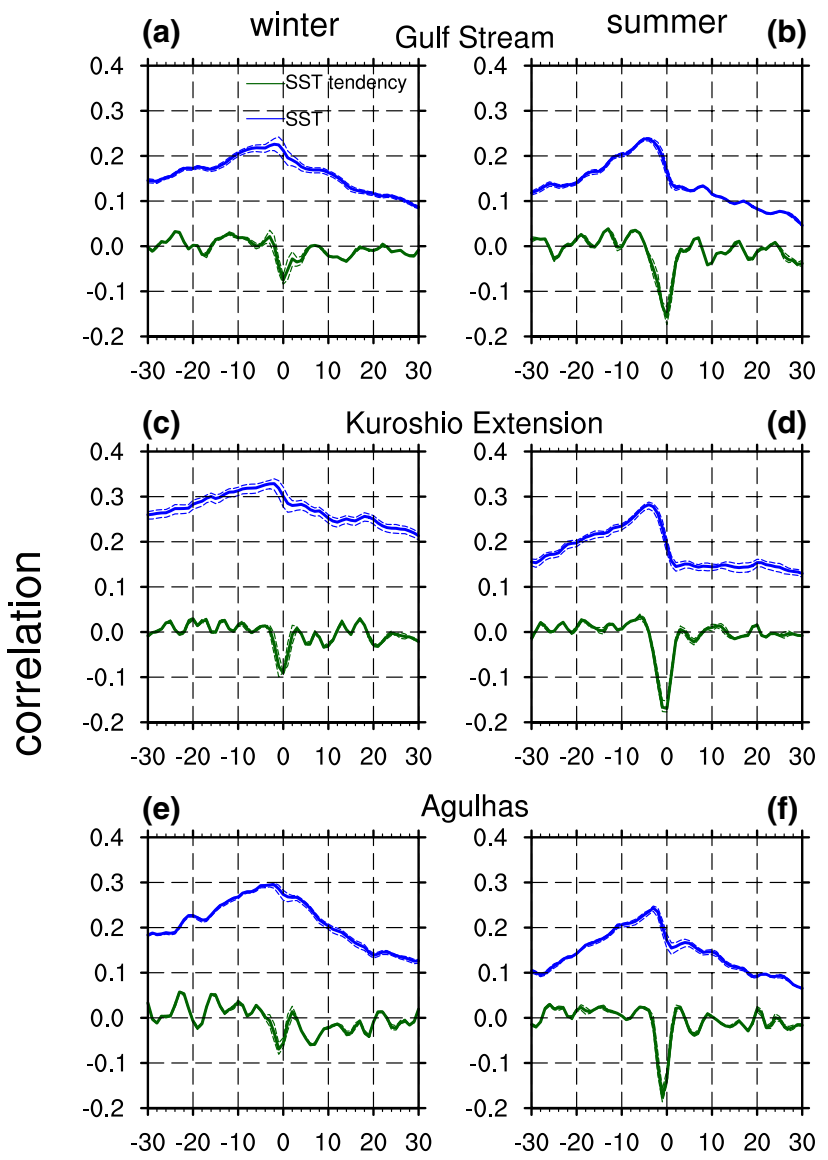
Agulhas

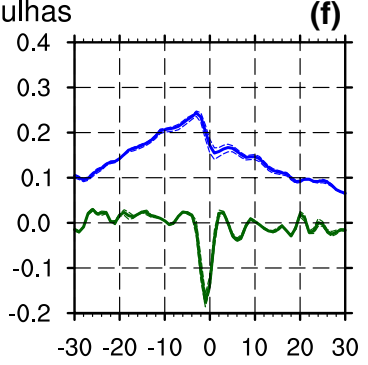

SST/SSTtend lags [day]

Fig. 4 Lead-lag correlation of SHF-SST (blue solid curves) and SHF-SST tendency (green solid curves) in winter (NDJFM/MJJAS in the Northern/Southern Hemisphere) (left panels) and summer (MJJAS/NDJFM in the Northern/Southern Hemisphere) (right panels) at the black diamond locations a, b within the Gulf Stream, c, $\mathbf{d}$ within the Kuroshio Extension, and $\mathbf{e}, \mathbf{f}$ within the Agulhas Return Flow in Fig. 3. Dashed lines denote the error margins of the correlation coefficients. $\mathrm{X}$ axis represents SST/SST tendency leading (left) and lagging (right) time in days. $\mathrm{Y}$ axis represents the correlation coefficient 
(a) winter N Atlantic SG summer (b)
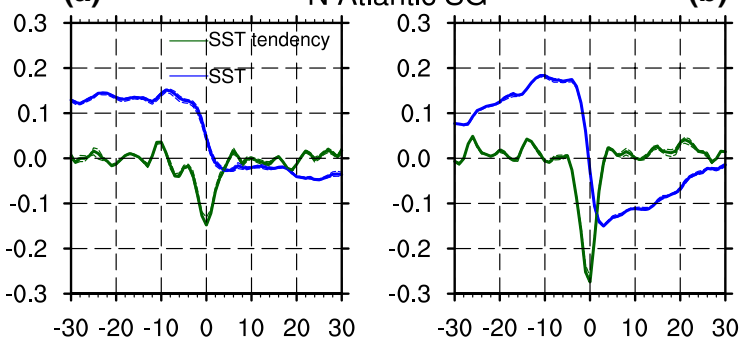

(c)

N Pacific SG

(d)
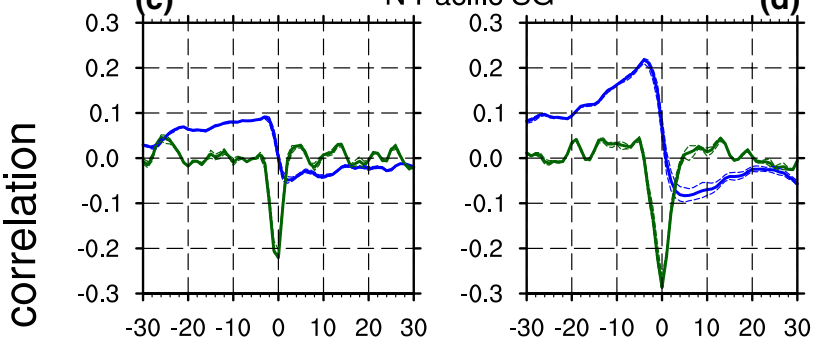

(e)

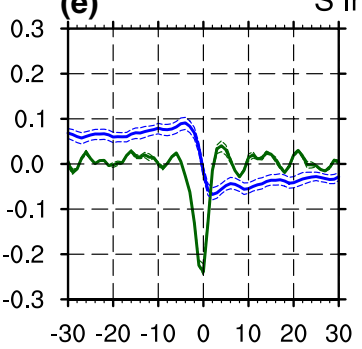

S Indian SG

(f)

\section{SST/SSTtend lags [day]}

Fig. 5 As Fig. 4 except for the black diamond locations $\mathbf{a}$, b within the North Atlantic subtropical gyre, $\mathbf{c}, \mathbf{d}$ within the North Pacific subtropical gyre, and e, $\mathbf{f}$ within the Southern Ocean subtropical gyre in Fig. 3

a feature of the oceanic forcing (Barsugli and Battisti 1998; Wu et al. 2006; Bishop et al. 2017), which occurs due to the role of oceanic processes in the SST change in the large SST gradient regions (Bishop et al. 2017).

In summer, the SHF-SST correlation curves display an obvious asymmetric structure about the zero lag in the Gulf Stream (Fig. 4b), Kuroshio Extension (Fig. 4d), and ARC (Fig. 4f). The SHF-SST tendency correlation has a large negative value at the zero lag. These features tell that higher SST is followed by larger SHF that is accompanied by a negative SST tendency, indicative of oceanic forcing with atmospheric feedback (Fig. 1b). Compared to winter, the negative SHF-SST tendency correlation is apparently larger. This means a stronger atmospheric forcing in the WBCs in summer than in winter, which may be related to smaller ocean mixed-layer depth in boreal summer than in boreal winter (Wu and Kinter 2010). (a) winter Arabian Sea summer (b)
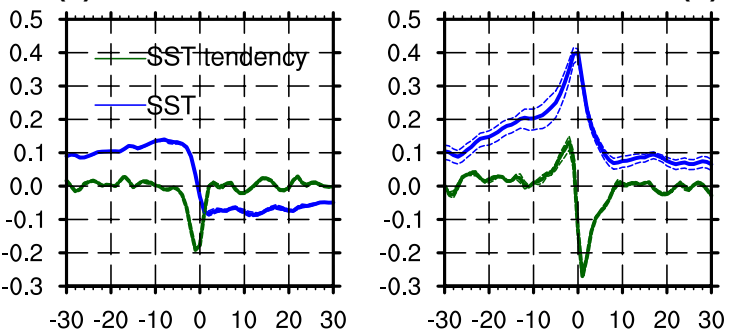

(c)

Bay of Bengal

(d)
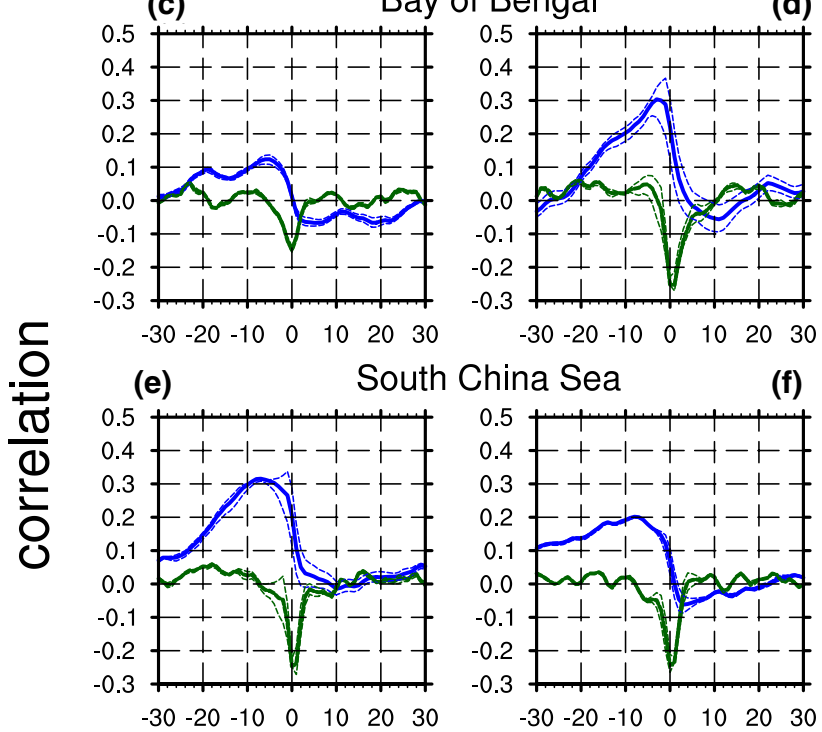

(g)

Philippine Sea

(h)
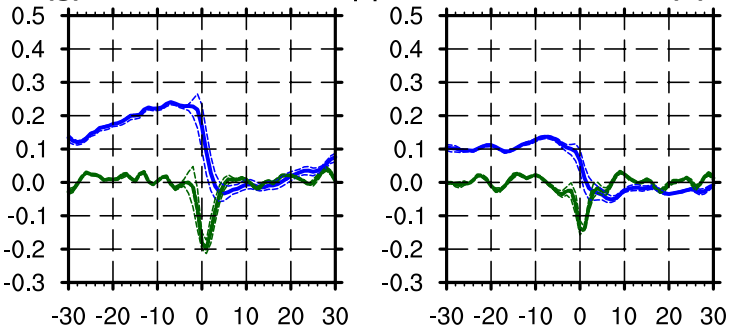

SST/SSTtend lags [day]

Fig. 6 As Fig. 4 except for the black diamond locations within $\mathbf{a}, \mathbf{b}$ the Arabian Sea, $\mathbf{c}, \mathbf{d}$ the Bay of Bengal, $\mathbf{e}, \mathbf{f}$ the South China Sea, and g, h the Philippine Sea in Fig. 3

In the subtropical gyre regions, the SHF-SST correlation curves display asymmetric features, accompanied by negative SHF-SST tendency correlation at the zero lag in the North Atlantic (Fig. 5a, b), North Pacific (Fig. 5c, d), and South Indian Ocean (Fig. 5e, f). This is indicative of the atmospheric forcing (Fig. 1a) (Barsugli and Battisti 1998; Wu et al. 2006; Bishop et al. 2017). In comparison, the change of the SHF-SST correlation across the zero lag and the magnitude of the negative SHF-SST tendency correlation coefficient at the zero lag are larger in summer than in 
winter. This difference suggests a stronger atmospheric forcing in the subtropical gyre regions in summer than in winter, which may be due to the shallower ocean mixed-layer depth in those regions in summer than in winter (Wu et al. 2015).

In winter, the SHF-SST correlation in the tropical North Indian Ocean and western North Pacific displays asymmetric feature across the zero lag, accompanied by negative SHF-SST tendency correlation at the zero lag at all the four locations (Fig. 6a, c, e, g). This confirms the atmospheric effect on the SST change in the above regions. The largest negative SHF-SST tendency correlation is observed in the South China Sea. The atmospheric wind effect on the intraseasonal SST change in the South China Sea during boreal winter has been illustrated in previous studies ( $\mathrm{Wu}$ et al. 2015; Wu and Chen 2015; Wu 2016) showed that large intraseasonal SST anomalies in the South China Sea are formed largely due to wind-related surface LHF changes associated with the East Asian winter monsoon. Wu et al. (2015) identified largest LHF-SST tendency correlation in the South China Sea region during boreal winter.

In summer, the SHF-SST correlation displays notable differences among the four locations. In the Arabian Sea, the correlation displays a typical ocean-driven feature with a large positive SHF-SST correlation at the zero lag (Fig. 6b) (Wu et al. 2006; Bishop et al. 2017). This is likely related to the large SST gradient in the Arabian Sea (not shown) induced by strong southwesterly summer monsoon wind that causes upwelling of cooler subsurface waters off the African coast. The large SST gradient leads to a role of the ocean advection in the SST change. In the Bay of Bengal, the SHF-SST correlation reaches the peak when SST leads SHF at about 3 days and the SHF-SST tendency correlation curve shows a symmetric pattern about the zero lag (Fig. 6d). In the South China Sea, the SHF-SST and SHF-SST tendency correlation displays features similar to those in the Bay of Bengal except for a larger lead time of the peak positive SHF-SST correlation (Fig. 6f). The above lead-lag correlations suggest both atmosphere-driven and ocean-driven features in the Bay of Bengal and South China Sea. In the Philippine Sea, the SHF-SST correlation shows asymmetric feature across the zero lag, accompanied by negative SHF-SST tendency correlation at the zero lag (Fig. 6h), indicative of an atmosphere-driven feature. This is likely due to large intraseasonal SHF perturbations in the Philippine Sea that contribute to the SST change (Ye and Wu 2015; Wu et al. 2015). Both the positive SHF-SST and negative SHF-SST tendency correlations are larger compared to those in winter. According to the above analysis, the role of the oceanic forcing decreases and the atmospheric forcing increases from west to east in the tropical North Indian Ocean and western North Pacific region in summer.

Similar temporal evolutions in the lead-lag correlation at the selected mid-latitude locations are obtained based on the J-OFURO data (not shown). In comparison, the positive SHF-SST correlation tends to be larger, whereas the negative SHF-SST SST tendency tends to be smaller based on the J-OFURO data. Similar temporal evolutions in the lead-lag correlation are also seen at the tropical North Indian Ocean-western North Pacific locations in winter with slight differences in the magnitude of correlation coefficient (not shown). The magnitudes of positive SHF-SST correlation and negative SHF-SST tendency correlation in summer are much smaller at the tropical North Indian Ocean and western North Pacific locations based on the J-OFURO data (not shown).

\section{Time scale dependence of lead-lag correlation at different locations}

The dependence of the SHF and SST relationship on the time scale has been illustrated by Bishop et al. (2017) for the mid-latitude regions based on monthly data and Small et al. (2019) for the North Pacific based on smoothed daily data with different filtering windows. In this section, we extend the analysis using daily data that allows examination of lead-lag correlation with time lead/lag shorter than 30 days. Our analysis also covers the tropical North Indian Oceanwestern North Pacific region. Several previous studies have identified the difference of the SHF-SST and SHF-SST tendency relationship between the 10-20-day and 30-60day intraseasonal variations in that region (Wu et al. 2015; Ye and Wu 2015). The selected mid-latitude locations of examining the time scale dependence of lead-lag correlation are the same as those in the previous section. The lead-lag correlation is calculated based on all the days (Fig. 7) and the days in winter and summer (Figs. 8, 9, 10).

In the Gulf Stream region, the SHF-SST correlation is positive with the magnitude and lead time of peak correlation coefficient increasing with the time scale (Fig. 7a). The value of peak SHF-SST correlation coefficient increases from 0.3 at 2 -day time scale to 0.6 at 90 -day time scale. This may indicate a larger oceanic forcing with smoother data, which may be due to the reduced high frequency variability. The SHF-SST tendency correlation shows a clear asymmetric distribution and the lag time of maximum negative SHF-SST tendency correlation increases with the time scale (Fig. 7b). Similar variation of the SHF-SST and SHF-SST tendency correlation is observed in the Kuroshio Extension and ARC regions (not shown). The above feature indicates a dominance of oceanic forcing up to 90 days in the WBC and ARC regions.

In the South China Sea region, the SHF-SST correlation shows an asymmetric feature about the zero lag with the magnitude and lead time of peak positive correlation increasing with the time scale (Fig. 7c). The SHF-SST 

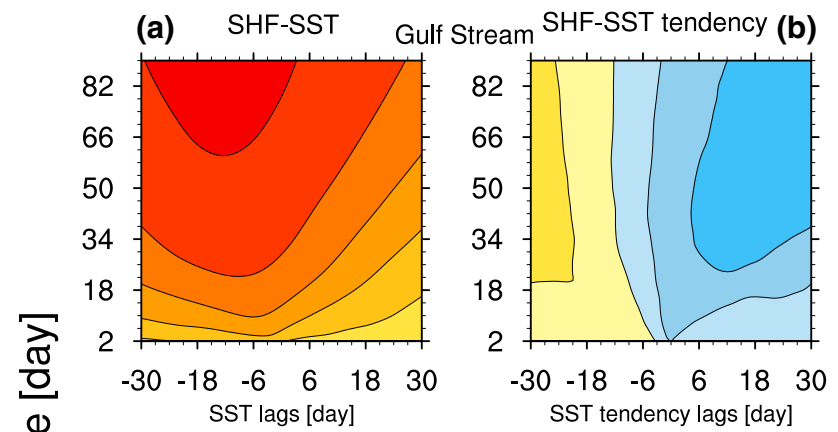

(c)

South China Sea

(d)
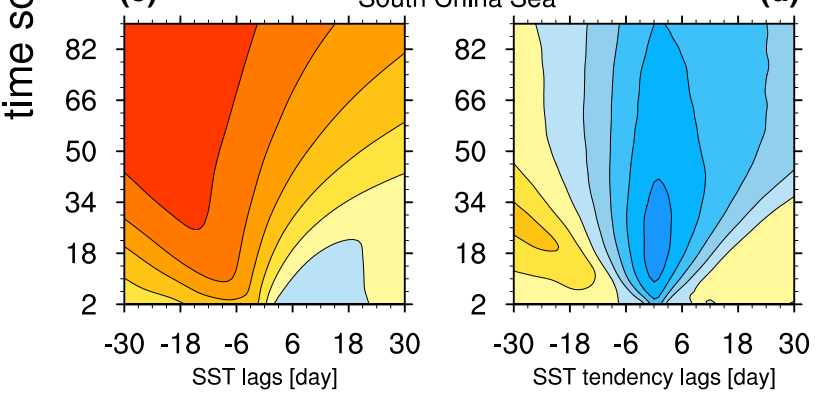

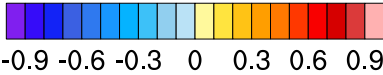

Fig. 7 Time-scale dependence of lead-lag correlation in $\mathbf{a}, \mathbf{b}$ the Gulf Stream and $\mathbf{c}$, $\mathbf{d}$ the South China Sea. Left panels are the SHF-SST correlation. Right panels are the SHF-SST tendency correlation. X axis represents SST/SST tendency leading (left) and lagging (right) time in days. $\mathrm{Y}$ axis represents the time scale (days)

tendency correlation displays a symmetric pattern with the magnitude of correlation first increasing up to 20-day time scale and then decreasing with the time scale (Fig. 7d). Similar features are observed in the Arabian Sea, Bay of Bengal, and Philippine Sea (not shown). These features indicate an atmospheric forcing of SST change in the above regions. In comparison, the correlation is larger in the South China Sea and Philippine Sea than in the Arabian Sea and Bay of Bengal.

In winter, in the Kuroshio Extension region, the positive SHF-SST correlation displays a symmetric feature with the magnitude of peak positive correlation increasing with the time scale (Fig. 8a). The SHF-SST tendency correlation displays an antisymmetric feature up to 90 days (Fig. 8b). The above changes in the lead-lag correlation with the time scale are similar to those of ocean-driven case in the stochastic model (Fig. 2c, f). Similar features are seen in the Gulf Stream and ARC regions (not shown). These features indicate a dominant oceanic forcing on time scales up to 90 days or longer in the $\mathrm{WBC}$ and $\mathrm{ARC}$ regions in winter.

In summer, the positive SHF-SST correlation extends up to 90 days in the Kuroshio Extension region (Fig. 8c). The magnitude and lead time of peak positive correlation
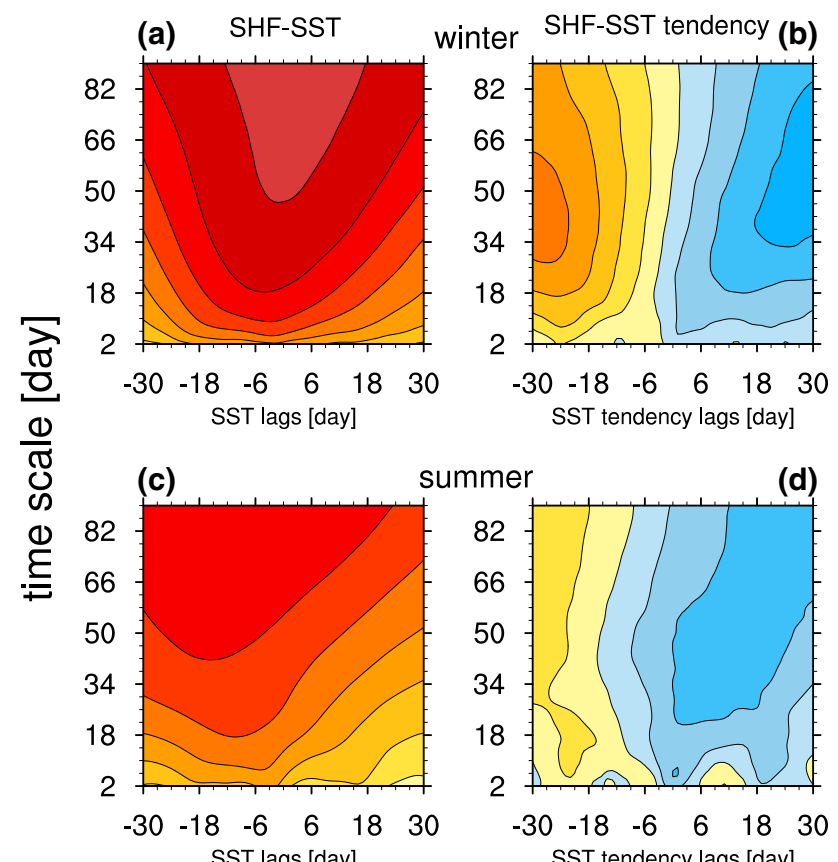

summer

(d)

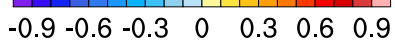

Fig. 8 Time-scale dependence of lead-lag correlation in the Kurosho Extension in $\mathbf{a}, \mathbf{b}$ winter and $\mathbf{c}, \mathbf{d}$ summer. Left panels are the SHFSST correlation. Right panels are the SHF-SST tendency correlation. $\mathrm{X}$ axis represents SST/SST tendency leading (left) and lagging (right) time in days. $\mathrm{Y}$ axis represents the time scale (days)

increases with the time scale. Negative SHF-SST tendency correlation is seen around zero lag for time scales below 20 days (Fig. 8d). Above 20-day time scales, the SHF-SST tendency correlation displays an asymmetric feature. The above changes in the lead-lag correlation are similar to those of oceanic forcing with atmospheric feedback in the stochastic model (Fig. 2b, d) but with a larger negative SHF-SST tendency correlation. Similar features are seen in the Gulf Stream and ARC regions except for smaller correlation coefficients in the Gulf Stream region (not shown). The above features suggest that the relative effect of atmospheric and oceanic forcing depends upon the time scale in the WBC and ARC regions in summer. The change of the relationship in summer from shorter to longer time scale may be related to the change in the SHF variance. Wu et al. (2015) showed the LHF variance in the western North Pacific is larger on 10-20-day time scale than on 30-60-day time scale.

In winter, in the Arabian Sea, the SHF-SST correlation is asymmetric about the zero lag and the negative SHF-SST tendency correlation is observed at the zero lag up to time scale of 40 days (Fig. 9a). These features are similar to the atmosphere-driven case in the stochastic model (Fig. 2a, d). 


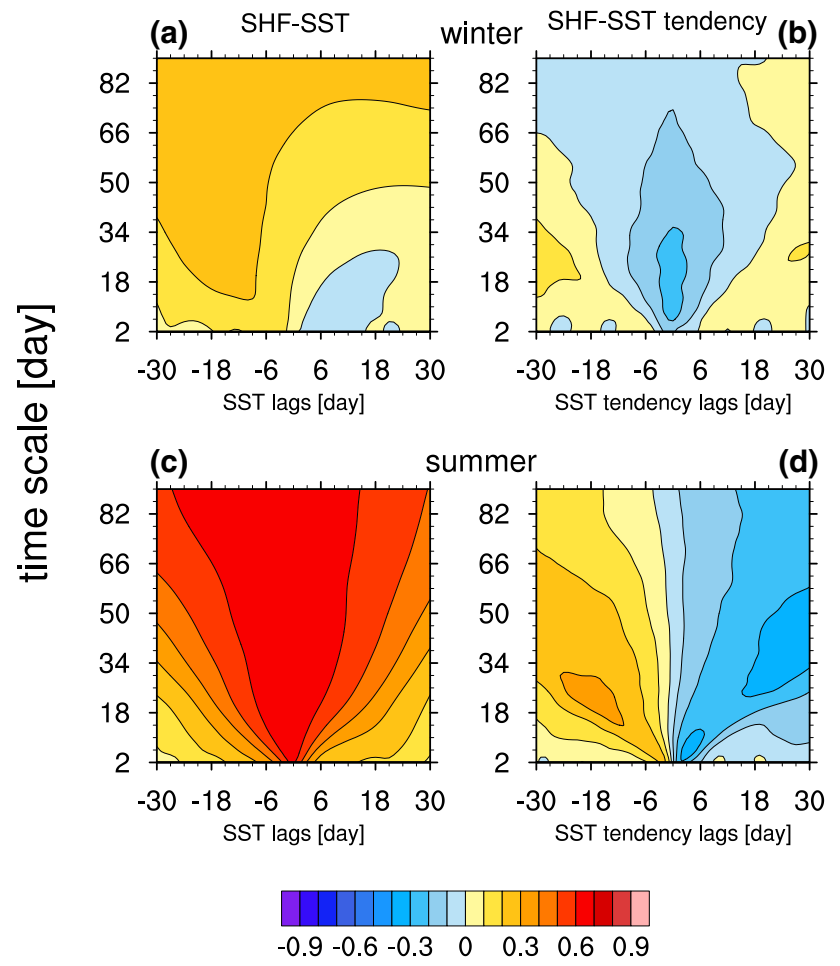

Fig. 9 As Fig. 8 except for the Arabian Sea
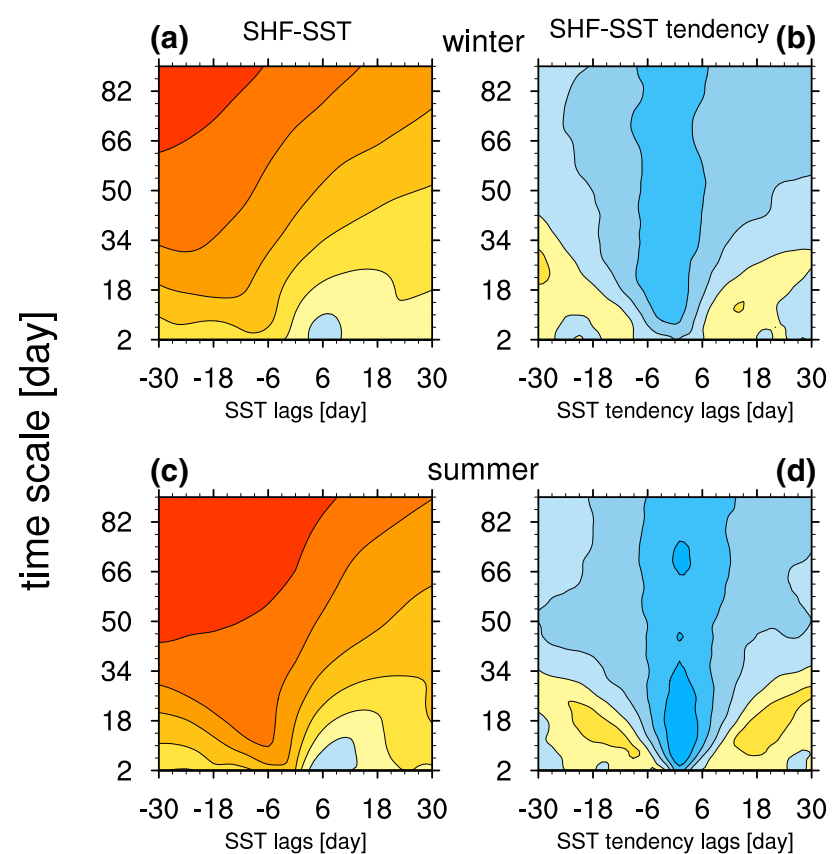

summer
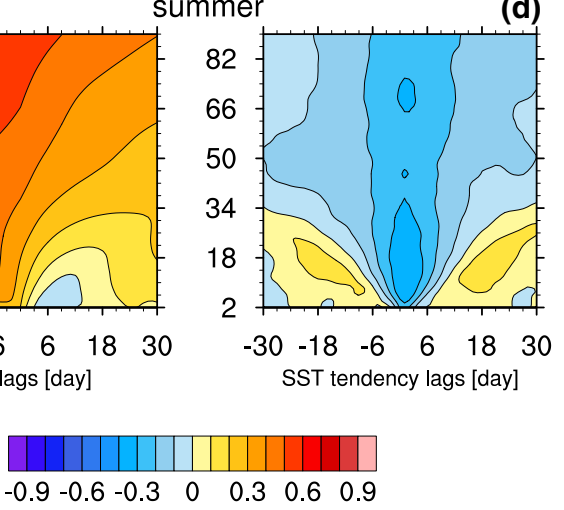

Fig. 10 As Fig. 8 except for the Philippine Sea
Beyond 40 days, the asymmetric feature of the SHF-SST correlation weakens, so does the negative SHF-SST tendency correlation (Fig. 9b). These results indicate that the SHF effect on the SST change is limited to time scales below 40 days in the Arabian Sea and the SST effect on SHF starts to appear beyond that. This may be related to the change of the SHF variance that tends to be larger on short time scales (not shown). In summer, in the Arabian Sea, the SHF-SST correlation is large positive and symmetric about the zero lag (Fig. 9c), and the SHF-SST tendency correlation is asymmetric up to the time scale of 90 days (Fig. 9d). These features resemble the ocean-driven case in the stochastic model (Fig. 2c, f). It suggests a dominance of oceanic forcing in the Arabian Sea in summer, which may be related to the large zonal SST gradient in the summer monsoon season so that the ocean advection contributes largely to the SST change.

In winter, in the Philippine Sea, the asymmetric SHF-SST correlation extends up to 90-day time scale, and the lead time of maximum positive SHF-SST correlation increases with the time scale (Fig. 10a). The symmetric negative SHF-SST tendency correlation covers the time scales from a few days to 90 days (Fig. 10b). The above changes in the lead-lag correlation are similar to those in Fig. 2a, d. These features denote the SHF effect on the SST change in the Philippine Sea, which may be related to active synoptic activity and large intraseasonal oscillation. In summer, similar features of the SHF-SST and SHF-SST tendency correlation are seen in the Philippine Sea (Fig. 10c, d). Note that large positive SHF-SST correlation expands to the lag time, indicative of an oceanic forcing at time scale above 40 days.

In winter, the SHF-SST and SHF-SST tendency correlations in the Bay of Bengal and South China Sea (Figs. 11a, b, 12a, b) are similar to those in the Philippine Sea. In summer, the SHF-SST ad SHF-SST tendency correlations in the Bay of Bengal and South China Sea (Figs. 11c, d, 12c, d) show features similar to those in the Philippine Sea at time scales below 40 days but similar to those in the Arabian Sea at time scales above 40 days. This suggests both oceanic forcing and atmospheric forcing in the two regions, depending upon the time scale.

\section{Summary and discussions}

This study examines the SHF and SST relationship in the mid-latitude SST frontal zones, subtropical gyre regions, and tropical North Indian Ocean-western North Pacific region using daily SHF and SST data. The SHF and SST relationship in winter and summer is compared for specific locations. The time scale dependence of the SHF and SST relationship is examined for winter and summer respectively. The use of daily SHF and SST data allows the investigation 


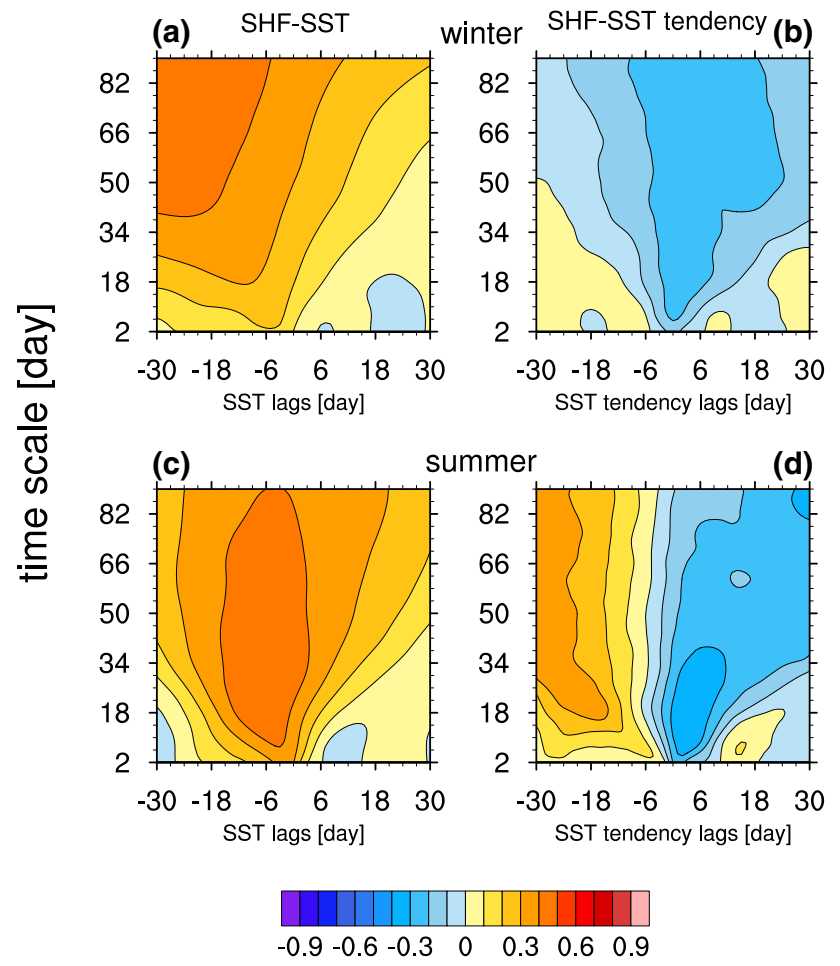

Fig. 11 As Fig. 8 except for the Bay of Bengal

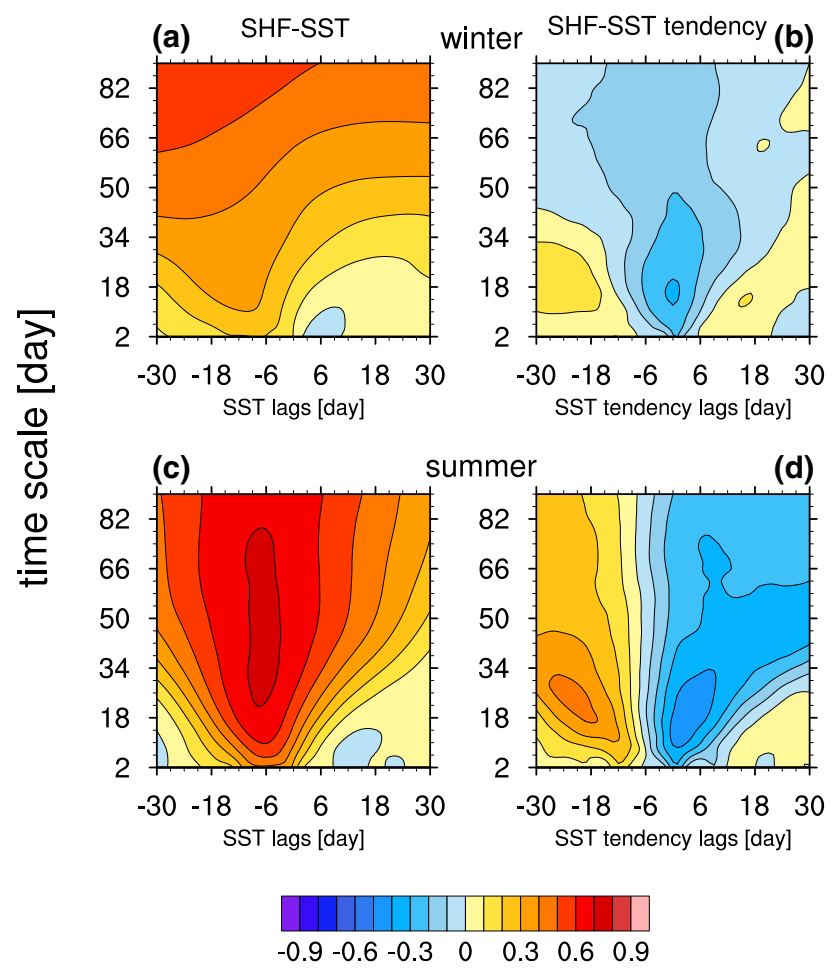

Fig. 12 As Fig. 8 except for the South China Sea of the relationship between SHF and SST variations with lead and lag time shorter than 1 month. The main results of seasonal changes and time scale dependence of SHF and SST relationship are summarized in Table 2.

The SHF and SST relationship displays pronounced differences in the mid-latitude SST frontal zones and subtropical gyre regions. In the $\mathrm{WBC}$ and ARC regions, the oceanic forcing is dominant. In the subtropical gyre regions, the atmospheric forcing is dominant. In the tropical North Indian Ocean-western North Pacific region, the atmospheric forcing is larger in the South China Sea than in the Arabian Sea and Bay of Bengal.

The SHF and SST relationship displays seasonal change in the mid-latitude SST frontal zones, subtropical gyre regions, and tropical Indo-western Pacific region. In the WBC and ARC regions, the oceanic forcing is larger in winter than in summer. Atmospheric forcing is detected in those regions in summer in addition to the oceanic forcing. In the subtropical gyre regions, atmospheric forcing is and larger in summer than in winter. In the Arabian Sea, the atmospheric forcing is dominant in winter, but the oceanic forcing is dominant in summer. The atmospheric forcing in the Philippine Sea is larger in winter than in summer. In the Bay of Bengal and the South China Sea, atmospheric forcing is dominant in winter and the oceanic forcing is accompanied by atmospheric feedback in summer.

The relationship between SST and SHF variations displays different time scale dependence in winter and summer. In the WBC and ARC regions, the ocean forcing is dominant up to 90-day time scales in winter. In summer, the atmospheric forcing is limited to time scales shorter than 20 days and the oceanic forcing is dominant on time scales above 20 days. In winter, the atmospheric forcing is dominant up to 90-day time scales in the Bay of Bengal, the South China Sea, and the Philippine Sea. In the Arabian Sea, the atmospheric forcing is limited to time scales below 40 days beyond which there is weak oceanic forcing. In summer, the oceanic forcing is dominant up to 90-day time scales in the Arabian Sea. In the Philippine Sea, the atmospheric forcing is large on time scales shorter than 40 days and the oceanic forcing appears on time scales longer than 40 days. In the Bay of Bengal and the South China Sea, atmospheric forcing is seen up to 40-day time scales and oceanic forcing shows up beyond 40-day time scale.

These results have important implications for future studies of the air-sea relationship. Our analysis, combined with previous studies, indicates that the difference of the SHF and SST relationship between the mid-latitude SST frontal zones and the subtropical gyre regions is extended from daily to monthly time scales. The prominent difference in the correlation between winter and summer suggests the necessity of examining the air-sea relationship for winter and summer separately. The changes in the atmospheric and 
Table 2 Summary of seasonal change and time scale dependence of SHF and SST relationship in different regions

\begin{tabular}{lll}
\hline Location & Winter & Summer \\
\hline $\begin{array}{l}\text { Gulf Stream } \\
\text { Kuroshio Extension } \\
\begin{array}{l}\text { Subthas Return Current } \\
\text { Arabian Sea }\end{array}\end{array}$ & ocn up to 90 days & $\begin{array}{l}\text { atm below } 20 \text { days } \\
\text { ocn above } 20 \text { days }\end{array}$ \\
Philippine Sea & $\begin{array}{l}\text { atm up to } 90 \text { days } \\
\text { atm below } 40 \text { days } \\
\text { weak ocn above } 40 \text { days }\end{array}$ & $\begin{array}{l}\text { atm up to } 90 \text { days } \\
\text { ocn up to } 90 \text { days }\end{array}$ \\
$\begin{array}{l}\text { atm up to } 90 \text { days } \\
\text { South China Sea }\end{array}$ & atm up to 90 days & $\begin{array}{l}\text { atm below } 40 \text { days } \\
\text { ocn above } 40 \text { days }\end{array}$ \\
\hline
\end{tabular}

"atm" and "ocn" denote atmospheric forcing and oceanic forcing, respectively oceanic forcing with the time scale point to the importance of taking into account the time scale when investigating the air-sea interactions in different seasons and in different regions. Several transitions between the atmospheric and oceanic forcing have been detected at certain submonthly time scales. This includes the change from the atmospheric forcing to the oceanic forcing at about 20-day time scale in summer in the WBC and ARC regions, from the atmospheric forcing to weak oceanic forcing around 40-day time scale in winter in the Arabian Sea, and from the atmospheric forcing to the oceanic forcing around 40-day time scale in summer in the Philippine Sea. The plausible reasons for such transitions remain to be investigated in future studies.

Model simulations are often used in climate studies. Given the importance of air-sea coupling mechanisms in the climate variability, it is necessary to perform a diagnosis of the air-sea relationship in the model simulations, which will help to understand the limitation of the results obtained based on model simulations. For example, how is the SHF and SST relationship in winter and summer in the model simulations compared to the observations? How does the SHF and SST relationship vary with the time scale in the models?

Acknowledgements Comments from two anonymous reviewers have helped the significant improvement of this paper. This study is supported by the National Key Research and Development Program of China Grant (2016YFA0600603) and the National Natural Science Foundation of China Grants (41721004). The NOAA OISST v2.0 data were obtained from ftp://ftp.cdc.noaa.gov/Datasets/noaa.oisst.v2.highr es/. The OAFlux flux data from were obtained from ftp://ftp.whoi.edu/ pub/science/oaflux/data_v3/daily/turbulence/. The J-OFURO flux data were obtained from http://dtsv.scc.u-tokai.ac.jp/j-ofuro/.

Open Access This article is licensed under a Creative Commons Attribution 4.0 International License, which permits use, sharing, adaptation, distribution and reproduction in any medium or format, as long as you give appropriate credit to the original author(s) and the source, provide a link to the Creative Commons licence, and indicate if changes were made. The images or other third party material in this article are included in the article's Creative Commons licence, unless indicated otherwise in a credit line to the material. If material is not included in the article's Creative Commons licence and your intended use is not permitted by statutory regulation or exceeds the permitted use, you will need to obtain permission directly from the copyright holder. To view a copy of this licence, visit http://creativecommons.org/licenses/by/4.0/.

\section{References}

Barsugli JJ, Battisti DS (1998) The basic effects of atmosphere-ocean thermal coupling on midlatitude variability. J Atmos Sci 55:477493. https://doi.org/10.1175/1520-0469(1998)0552.0.CO;2

Bishop SP, Small RJ, Bryan FO, Tomas RA (2017) Scale dependence of midlatitude air-sea interaction. J Clim 30:8027-8221. https:// doi.org/10.1175/JCLI-D-17-0159.1

Cayan DR (1992) Latent and sensible heat flux anomalies over the northern oceans: driving the sea surface temperature. J Phys Oceanogr 22:859-881. https://doi.org/10.1175/15200485(1992)022<0859:LASHFA > 2.0.CO;2

Deser C, Timlin MS (1997) Atmosphere-ocean interaction on weekly timescales in the North Atlantic and Pacific. J Clim 10:393-408. https://doi.org/10.1175/1520-0442(1997)010<0393:AOIOW $\mathrm{T}>2.0 . \mathrm{CO} ; 2$

Duvel JP, Vialard J (2007) Indo-Pacific sea surface temperature perturbations associated with intraseasonal oscillations of tropical convection. J Clim 20:3056-3082. https://doi.org/10.1175/JCLI4 144.1

Frankignoul C (1985) Sea surface temperature anomalies, planetary waves, and air-sea feedback in the middle latitudes. Rev Geophys 23:357-390. https://doi.org/10.1029/RG023i004p00357

Frankignoul C, Hasselmann K (1977) Stochastic climate models, part II. Application to sea-surface temperature anomalies and thermocline variability. Tellus 29:289-305. https://doi.org/10.3402/ tellusa.v29i4.11362

Frankignoul C, Czaja A, L'Heveder B (1998) Air-sea feedback in the North Atlantic and surface boundary conditions for ocean models. J Clim 11:2310-2324. https://doi.org/10.1175/15200442(1998)011<2310:ASFITN>2.0.CO;2

Hasselmann K (1976) Stochastic climate models part I. Theory. Tellus 28:473-485. https://doi.org/10.3402/tellusa.v28i6.11316

Jin $\mathrm{Z}$ et al (2020) Maintenance of mid-latitude oceanic fronts by mesoscale eddies. Sci Adv 6:eaba7880. https://doi.org/10.1126/sciad v.aba7880

Kitoh A, Arakawa O (1999) On overestimation of tropical precipitation by an atmospheric GCM with prescribed SST. Geophys Res Lett 26:2965-2968. https://doi.org/10.1029/1999g1900616 
Kumar A, Hoerling MP (1998) Specification of regional sea surface temperatures in atmospheric general circulation model simulations. J Geophys Res 103:8901-8907. https://doi. org/10.1029/98jd00427

Lau N-C, Nath MJ (2000) Impact of ENSO on the variability of the Asian-Australian monsoons as simulated in GCM experiments. J Clim 13:4287-4309. https://doi.org/10.1175/15200442(2000)013<4287:IOEOTV > 2.0.CO;2

Lau N-C, Nath MJ (2003) Atmosphere-ocean variations in the IndoPacific sector during ENSO episodes. J Clim 16:3-20. https:// doi.org/10.1175/1520-0442(2003)016<0003:AOVITI > 2.0.CO;2

Preisendorfer RW (1988) Principal component analysis in meteorology and oceanography. In: Developments in atmospheric sciences, edn 17. Elsevier Science Publishers, Amsterdam, pp 402-418

Reynolds RW, Smith TM, Liu C, Chelton DB, Casey KS, Schlax MG (2007) Daily high-resolution-blended analyses for sea surface temperature. J Clim 20:5473-5496. https://doi.org/10.1175/2007J CLI1824.1

Small RJ, Bryan FO, Bishop SP, Tomas RA (2019) Air-sea turbulent heat fluxes in climate models and observational analyses: what drives their variability? J Clim 32:2397-2421. https://doi. org/10.1175/JCLI-D-18-0576.1

Sperber KR, Palmer TN (1996) Interannual tropical rainfall variability in general circulation model simulations associated with the Atmospheric Model Intercomparison Project. J Clim 9:27272750. https://doi.org/10.1175/1520-0442(1996)009<2727:ITRVI $\mathrm{G}>2.0 . \mathrm{CO} ; 2$

von Storch JS (2000) Signature of air-sea interactions in a coupled atmosphere-ocean GCM. J Clim 13:3361-3379. https://doi. org/10.1175/1520-0442(2000)013<3361:SOASII>2.0.CO;2

Wallace JM, Smith C, Jiang Q (1990) Spatial patterns of atmosphereocean interaction in the northern winter. J Clim 3:990-998. https://doi.org/10.1175/1520-0442(1990)003<0990:SPOAO $\mathrm{I}>2.0 . \mathrm{CO} ; 2$

Wang B, Ding Q, Fu X, Kang I-S, Jin K, Shukla J, Doblas-Reyes F (2005) Fundamental challenge in simulation and prediction of summer monsoon rainfall. Geophys Res Lett 32:L15711. https:// doi.org/10.1029/2005g1022734

Wu R (2016) Coupled intraseasonal variations in the East Asian winter monsoon and the South China Sea-western North Pacific SST in boreal winter. Clim Dyn 47:2039-2057. https://doi.org/10.1007/ s00382-015-2949-7

Wu R (2019) Summer precipitation-SST relationship on different time scales in the northern tropical Indian Ocean and western Pacific. Clim Dyn 52:5911-5926. https://doi.org/10.1007/s0038 2-018-4487-6

Wu R, Chen Z (2015) Intraseasonal SST variations in the South China Sea during boreal winter and impacts of the East Asian winter monsoon. J Geophys Res Atmos 120:5863-5878. https://doi. org/10.1002/2015jd023368

Wu R, Kinter JL III (2010) Atmosphere-ocean relationship in the mid-latitude North Pacific: seasonal dependence and eastwest contrast. J Geophys Res Atmos 115:D06101. https://doi. org/10.1029/2009JD012579

Wu R, Kirtman BP (2004) Impacts of the Indian Ocean on the Indian summer monsoon-ENSO relationship. J Clim 17:3037-3054. https://doi.org/10.1175/1520-0442(2004)017<3037:IOTIO $\mathrm{O}>2.0 . \mathrm{CO} ; 2$

Wu R, Kirtman BP (2005) Roles of Indian and Pacific Ocean air-sea coupling in tropical atmospheric variability. Clim Dyn 25:155170. https://doi.org/10.1007/s00382-005-0003-x

Wu R, Kirtman BP (2007) Regimes of seasonal air-sea interaction and implications for performance of forced simulations. Clim Dyn 29:393-410. https://doi.org/10.1007/s00382-007-0246-9

Wu R, You T (2018) Summer intraseasonal surface heat flux-sea surface temperature relationship over Northern Tropical Indo-Western Pacific in climate models. J Geophys Res Atmos 123:58595880. https://doi.org/10.1029/2018jd028468

Wu R, Kirtman BP, Pegion K (2006) Local air-sea relationship in observations and model simulations. J Clim 19:4914-4932. https ://doi.org/10.1175/JCLI3904.1

Wu R, Kirtman BP, Pegion K (2007) Surface latent heat flux and its relationship with sea surface temperature in the National Centers for Environmental Prediction Climate Forecast System simulations and retrospective forecasts. Geophys Res Lett 34:L17712. https://doi.org/10.1029/2007g1030751

Wu R, Cao X, Chen S (2015) Covariations of SST and surface heat flux on 10-20 day and 30-60 day time scales over the South China Sea and western North Pacific. J Geophys Res Atmos 120:1248612499. https://doi.org/10.1002/2015jd024199

Ye K, Wu R (2015) Contrast of local air-sea relationships between 10-20-day and 30-60-day intraseasonal oscillations during May-September over the South China Sea and western North Pacific. Clim Dyn 45:3441-3459. https://doi.org/10.1007/s0038 2-015-2549-6

Yu L, Weller RA (2007) Objectively analyzed air-sea heat fluxes for the global ice-free oceans (1981-2005). Bull Amer Meteor Soc 88:527-540. https://doi.org/10.1175/BAMS-88-4-527

Publisher's note Springer Nature remains neutral with regard to jurisdictional claims in published maps and institutional affiliations. 